\title{
DOI 10.26886/2523-6938.1(1)2017.6
}

UDC 577.23

\section{ASPECTS OF THE DEMONSTRATION PROOFS OF THE BIOENERGETIC PHENOMENS}

\author{
V. V. Bocharova, PhD, MD
}

M. N. Lebedyuk, MD, PhD, DSc, Professor

Odessa National Medical University, Ukraine, Odessa

\section{V. Kuts, MD, PhD, DSc, Associate Professor}

Institute Sumy State University, Ukraine, Sumy

\section{K. V. Kolyadenko, PhD, MD, Associate Professor \\ O. O. Bogomol'tsa National Medical University, Ukraine, Kyiv}

Sabri Loussaief, PhD, MD

Tunisia (TN)

The subject matter of the research is to investigate the special feature of the arrangement of precipitations on the skin with certain dermatosis, which can be considered as "demonstrational" proofs of bioenergetic phenomena. Purpose of the work is to present to doctors the materials of the new demonstrative base of the appearance of precipitations with psoriasis, shingles, scleroderma, pityriasis rosea. The clinical research allows to assume that the appearance of precipitations "on the motion of scratching and micro-injuries" with psoriasis, "on the motion of nerves" with the shingles, "on the motion of the acupuncture meridians" with the scleroderma in the form the so-called "impact by sabre", "on the motion of lines the tensions of the skin" in the pityriasis rosea can be explained by bioenergetic phenomena.

Keywords: the bioenergetic aspects of the reasons for precipitations on the skin with dermatosis. 
${ }^{1}$ В. В. Бочарова, кандидат медицинских наук; ${ }^{1}$ М. Н. Лебедюк, доктор медицинских наук, профрессор; ${ }^{2} Л$. В. Куи, доктор медицинских наук, доцент; ${ }^{3}$ К. В. Коляденко, кандидат медицинских наук, доцент; ${ }^{4}$ Сабри Луссаиеф, доктор медицины и фрилософрии. Аспекты демонстрационных доказательств биоэнергетических френоменов / ${ }^{1}$ Одесский национальный медицинский университет, Украина, одесса; ${ }^{2}$ Медицинский институт Сумского государственного университета, Украина, Сумы; ${ }^{3}$ Национальный медицинский университет имени А. А. Богомольца, Украина, Киев; ${ }^{4}$ Тунис

Предмет исследования - особенности расположения высыпаний на коже при некоторых дерматозах, которые можно рассматривать как «демонстрационные» доказательства биоэнергетических феноменов. Цель работы - представить врачам материалы новой доказательной базы возникновения высыпаний при псориазе, опоясывающем лишае, склеродермии, розовом лишае Жибера. Проведенные клинические исследования позволяют предположить, что возникновение высыпаний «по ходу расчесов и микротравм» при псориазе, «по ходу нервов» при опоясывающем лишае, «по ходу акупунктурных меридианов» при склеродермии (в виде т. н. "удара саблей»), «по ходу линий растяжения кожи» при розовом лишае Жибера могут объясняться биоэнергетическими феноменами.

Ключевые слова: биоэнергетические аспекты причин высыпаний на коже при дерматозах.

Введение. Несмотря на многовековой опыт работы исследователей многих стран мира над проблемой особенностей высыпаний на коже при многих дерматозах, в большинстве случаев нельзя с уверенностью сказать, что мы в достаточно объективной форме понимаем причину уникальности форм первичных и вторичных 
морфологических элементов сыпи и их расположения в определенных участках тела при огромном количестве заболеваний кожи.

Цель работы - представить врачам материалы новой доказательной базы возникновения высыпаний при псориазе, опоясывающем лишае, склеродермии, розовом лишае Жибера.

Материалы и методы. Обследовано 50 больных псориазом в возрасте от 20 до 60 лет, мужчин - 23, женщин - 27. Диагноз устанавливался на основании анализа данных, полученных при выяснении жалоб, анамнеза заболевания и жизни, объективного и лабораторных исследований больных; клиническая картина у всех пациентов соответствовала диагнозу вульгарный псориаз средней степени распространенности и тяжести прогрессирующей стадии с сохраненной сезонностью обострений и рецидивов.

Результаты и их обсуждение. Наиболее часто первые клинические признаки псориаза появлялись в возрасте от 15 до 30 лет (44 - 88\%); провоцирующими фракторами возникновения изоморфной реакции кожи (феномена Кебнера) были механические раздражения: у $25(50 \%)$ - в результате длительного сдавливания без нарушения целостности кожи, у 25 (50\%) - в результате нарушения целостности кожи после инъекций, царапин и других микротравм. Наследственный анамнез указывал на наличие генетической предрасположенности у 22 больных. Среди фракторов, которые способствовали появлению псориаза, больные отмечали: влияние психоэмоционального стресса (у 12 - 24\%), перенесенную ангину или острые респираторные заболевания (у 4 - 8\%), общее переохлаждение (у 6 - 12\%); остальные пациенты не могли связать начала у них псориаза с действием какоголибо фрактора. Умеренные расстройства со стороны психоэмоциональной сферы отмечали 46 (92\%) пациентов. У 20 (40\%) обследованных высыпания на коже сопровождались зудом. 
Клинические данные свидетельствуют о том, что феномен Кебнера появляется, в среднем, через 2 недели после раздражения с появлением в соответствующих местах псориатических высыпаний.

Согласно положениям патофизиологии и патоморфологии, повреждение - это типовой патологический процесс, основой которого являются измения внутриклеточного гомеостаза, что приводит к нарушению структурной целостности клетки и ее функциональных свойств. В зависимости от механизмов инициации повреждения оно может быть насильственным и цитопатическим. В отношении к появлению изоморфной реакции кожи (феномену Кебнера) при псориазе имеет значение насильственное повреждение, которое развивается при действии на клетки и структуры клинически неизмененной кожи фризических или химических, биологических факторов, интенсивность которых превышает обычные возбуждающие влияния, к которым клетка адаптирована. Цитопатический вариант возникает в результате первичного нарушения защитнокомпенсаторных гомеокинетических механизмов клетки. В этом случае факторами, которые запускают патогенетические механизмы повреждения, являются природные для этой клетки возбуждающие стимулы, но которые в этих условиях становятся повреждающими. Такими повреждениями могут быть все виды, которые обусловлены отсутствием каких-либо необходимых для клетки компонентов (генетические дефекты, нарушения нервной трофики, антиоксидантная недостаточность, гипоксия и др.).

Таким образом, для развития изоморфной реакции кожи (феномена Кебнера) при псориазе имеют значение оба варианта повреждения. Повреждаться могут любые органоиды со сменой свойственных им функций: 
1) плазматическая мембрана - влияние на коэффрициент градиента веществ и системы их активного транспорта, нарушения клеточных рецепторов, межклеточных взаимодействий, смены антигенных свойств клеток;

2) митохондрии - угнетение процессов клеточного дыхания, разобщенность процессов окисление и фросфорилирования, что приводит к нарушениям энергообеспечения клеток;

3) эндоплазматический ретикулум - наступает дезагрегация полисом, в следствие чего нарушаются реакции биосинтеза белка в клетке; страдают процессы детоксикации, микросомального окисления и др.;

4) повышение проницаемости лизосомальных мембран приводит к выходу в цитоплазму гидролитических фрерментов;

5) В мышечных клетках нарушается способность саркоплазматического ретикулума депонировать ионы кальция и т. д.

Даже в реакциях, которые направлены на обеспечение функционального спокойствия клеток (с целью устранения возможных дополнительных нарушений внутриклеточного гомеостаза и сведения к минимуму энергетических затрат на выполнение специфических функций клеток), продукты соответствующих процессов (образование клеткой простагландинов и блокада ними бета-адренорецепторов; ингибирование аденилатциклазы и повышение активности фосфодиэстеразы, разрушающей цАМФ; образование аденозина природного блокатора кальциевых каналов и др.) могут не выполнить необходимой защиты, а наоборот - потенцировать ее повреждение.

Механическое повреждение, как и влияние антигенов, является существенным фрактором, который может привести к развитию воспаления. В ответ на механическое раздражение, благодаря аксонрефрлексу, происходит быстрое увеличение кровотока в коже (на 
начальном этапе), которое в дальнейшем приводит к пролонгированию местного раздражения, что в значительной мере зависит от освобождения эндотелиальными клетками оксида азота, который, наряду с норадреналином, играет обязательную роль посредника и в развитии собственно аксон-рефлекса и в дальнейшей т. н. «эндотелиальной дисфункции».

В то же время, несмотря на то, что такое объяснение является простым и понятным, но: 1) оно базируется не на прямых данных; 2) соответствующие структуры, которые обеспечивают аксон-рефлекс, гистологически пока еще не найдены; 3) в отношение самого феномена изоморфной реакции не проведено достаточного нейрофизиологического анализа.

Кроме влияния на кровоток, травма или сдавление кожи приводят к уменьшению объема подкожных венозных сосудов. При этом напряжение в гладкомышечных волокнах сосудистой стенки в начале резко снижается, но через несколько минут постепенно увеличивается; вместе с напряжением увеличивается и внутрисосудистое давление (т. н. «обратная релаксация» напряжения или последействия напряжения). Благодаря этому вены могут задерживать и выталкивать значительный объем крови без продолжительных изменений внутрисосудистого давления. Основными клетками-мишенями стенки венул, которые наиболее чувствительны к действию медиаторов, являются миоциты и эндотелиоциты.

Эндотелиоциты контактируют с большим количеством своих ближайших «соседей», их отростки проникают на разную глубину субэндотелиального слоя и контактируют как с клетками субэндотелия, так и с гладкомышечными клетками (миоцитами). Миоциты, в свою очередь, разделяются на 2 основные фрормы: контрактильные (kформа) и метаболические (m-форма). На механические стимулы 
отвечают k-миоциты (которые так же реагируют на электрические нервные и гуморальные стимулы процессом сокращения). В случае действия на сосудистую стенку механической травмы, они могут трансформироваться в М-миоциты. Особенностью к-миоцитов сосудистой стенки является то, что для них, как и для метасимпатической нервной системы (т. н. третья часть вегетативной нервной системы), важное значение имеет миогенный автоматизм. Инициаторами сокращения для k-миоцитов, как и для скелетных мышц, является нервный электрический импульс, но в гладкомышечных клетках, кроме этого, таких инициаторов может быть много и наиболее важными из них являются: механическое влияние, нервная стимуляция, гуморальная стимуляция (действие гормонов, биологически активных веществ, лекарственных препаратов, изменение химического состава интерстициальной жидкости); спонтанная инициация (без каких-либо внешних стимулов).

После механического влияния на ту или другую клетку происходит каскад биохимических реакций, активирующий продукцию медиаторов, которые в дальнейшем станут пусковыми факторами развития воспаления (пептидные гормоны местного действия, эйкозаноиды, биогенные амины и др.). Основными клетками-продуцентами медиаторов в зоне формирования псориатической сыпи являются: а) базофилы, моноциты, лимфоциты, нейтрофилы крови; б) кератиноциты, клетки Лангерганса, макрофаги, тучные клетки, Тлимфоциты-резиденты кожи; в) собственные клетки венул так же одновременно являются и клетками-мишенями и клеткамипродуцентами определенных медиаторов.

В венулах нервные окончания проникают по всей толще средней оболочки и не в отдельных участках, а по всей их длине. Ширина синаптической щели этих окончаний является небольшой. При такой 
узкой синаптической щели концентрация нейрогенного норадреналина около ближайших мышечных клеток увеличивается быстро и достигает высоких значений. После освобождения медиатор действует только в пределах своего синапса, и оттуда он (во всяком случае - большая его часть) снова быстро переходит благодаря активному захвату в нервную терминаль. Вследствие этого выход медиатора во внеклеточное пространство практически не происходит, и поэтому концентрация норадреналина за пределами синаптической щели через подпороговые для внесинаптических рецепторов величины, не имеет существенного функционального значения.

Несколько отличаются механизмы, которые происходят в отношении взаимодействия рецепторов с другими медиаторами. Особенностью реакций венозных сосудов при патологии (а возможно и предпатологии при псориазе, т. е. - в клинически не измененной коже) является то, что они втягиваются в рефлекторные реакции раньше, а их ответ более выражен, если сравнивать с резистентными сосудами. В подкожной вене человека значительно преобладают альфа-2-адренорецепторы. Активация «классических» альфаадренорецепторов (в частности, альфа-1, постсинаптических) обусловливает снижение уровня цАМФ в цитоплазме клетки, увеличение концентрации внутриклеточных оинов кальция, и вследствие этого - сокращение гладкомышечных клеток. Механизм дилятаторного действия бета-2-адренорецепторов связывают с принадлежностью к аденилатциклазной регулирующей системе. Активация этого типа рецепторов приводит к увеличению уровня цАМФ и уменьшению концентрации свободных ионов кальция в цитоплазме гладкомышечных клеток. С учетом того, что при псориазе уровень цАМФ снижен, можно предположить, что даже незначительное раздражение альфа-1-адренорецепторов вызывает 
ответную реакцию, например, в виде сокращения гладкомышечных клеток.

Неоднозначным является влияние адениновых нуклеотидов (АТФ, АДФ, АМФ) и нуклеозидов (аденозин) на электрическую и механическую активность гладкомышечных клеток венозных сосудов. Возбуждающее действие АТФ и, в меньшей мере - АМФ и аденозина связывают с наличием в мембранах гладкомышечных клеток $\mathrm{P}_{2^{-}}$ пуринорецепторов; АТФ и аденозин проявляют преимущественно тормозное действие на них. При анализе причин возникновения изоморфной реакции кожи (феномена Кебнера при псориазе) важным может быть тип механического раздражения: а) при механических раздражениях без нарушения целостности кожи (сдавливание и т. п.) во внеклеточном пространстве увеличивается концентрация адениновых нуклеотидов, источником которых являются поврежденные клетки и пуринергические нервные окончания; б) при механических раздражениях с нарушение целостности кожи (инъекции, травмы и т. п.) источниками адениновых нуклеотидов выступают и тромбоциты.

Реакция рецепторов на освобождение с клеток-продуцентов биогенных аминов так же имеет свои особенности и, если согласно данных одних исследователей, гистамин вызывает незначительное сужение вен, то согласно других данных - он увеличивает объем крови, который содержится в венах; однако, имеются сведения и о том, что гистамин вообще не способен инициировать какие-либо веномоторные реакции.

Серотонин является близким по своим биологическим функциям к гормонам, однако к тем из них, которые являются гуморальными регуляторными факторами неэндокринного происхождения (гистогормонов). Гистогормоны не отличаются дистантностью 
действия, однако могут осуществлять свое регулирующее влияние на чувствительные к ним клетки-мишени в месте своего образования (т. н. «изокринное» действие). Это изокринное действие серотонина в плане развития «изоморфной» реакции кожи при псориазе практически не изучалось, однако, с учетом его основного эффректа (регуляции психоэмоционального состояния), можно предположить его адаптогенно-трофическое влияние на фрунции нервной системы (во всяком случае - как «фон», на котором могут развиваться определенные местные патологические процессы, в т. ч. и феномен Кебнера). Выяснено, что серотонин, в зависимости от обстоятельств, может проявлять как сосудорасширяющее, так и сосудосуживающее действия: если эндотелий не поврежден, то наступает расслабление гладкомышечных клеток, обусловленное освобождением фракторов релаксации эндотелиального происхождения (EDRF - endothelium derived relaxing factor); если же целостность эндотелия нарушена, то происходит их сокращение, как следствие непосредственного действия на них указанных выше соединений. Т. е., возможно, что при феномене Кебнера в случае его появления после механических воздействий без повреждения кожи, серотонин расширяет венулы благодаря выделению EDRF, если же появление этого феномена обусловлено инъекциями, травмами или царапинами, то происходит обратный процесс - сокращение венул.

Таким образом, особенности расположения сыпи во время изоморфной реакции кожи при псориазе нуждается в тщательном исследовании, так как может «пролить свет» на разгадку появления и расположения высыпаний при очень многих дерматозах. В то же время, френомен Кебнера при псориазе можно рассматривать и как одно из «демонстрационных» доказательств такого нейрофизиологического (биоэнергетического) феномена как аксон- 
рефлекс, поскольку в ответ на механическое раздражение происходят рефлекторные процессы, которые осуществляются по разветвлениям аксонов без участия тела нейрона. В таких случаях возбуждение как бы идет по одной ветви аксона, затем - переходит на другую и уже по ней эффрерентно направляется к эффректорному органу (при псориазе - это структуры кожи и посткапиллярных венул).

В педагогическом плане не менее демонстрационным является и расположение «по ходу нервов» высыпании и при опоясывающем лишае, но не исключено, что причиной такой «демонстрации» является не аксон-рефлекс, а сложнейшие механизмы аутоиммунного реагирования со стороны клеток нервной ткани, в том числе приобретенных ними свойств для них не характерных эволюционно (например, функции антигенпрезентирующих клеток).

Однако, некоторые «демонстрационные» проявления на коже патологических процессов, которые происходят в организме, не всегда можно объяснить применяя определение «по ходу нервов», так как очаги поражения кожи не в полной мере располагаются именно так, однако их можно рассматривать как локализирующихся «по ходу акупунктурных меридианов», например, при такой форме коллагеноза как «склеродермия в виде удара саблей» (хотя это несомненно дискутабельно). Еще одним весьма «демонстрационным» явлением, но которое помогает уточнить диагноз, является расположение высыпаний при розовом лишае Жибера - по ходу линий Лангера (цветные демонстрационные материалы) - рис.

Выводы. «Демонстрационность» некоторых феноменов расположения сыпи при ряде дерматозов помогает врачам в установлении правильного диагноза. В то же время патофизиологические и патоморфологические основы таких проявлений высыпаний на коже еще крайне мало изучены. 

Демонстрационные проявления
высыпаний на коже

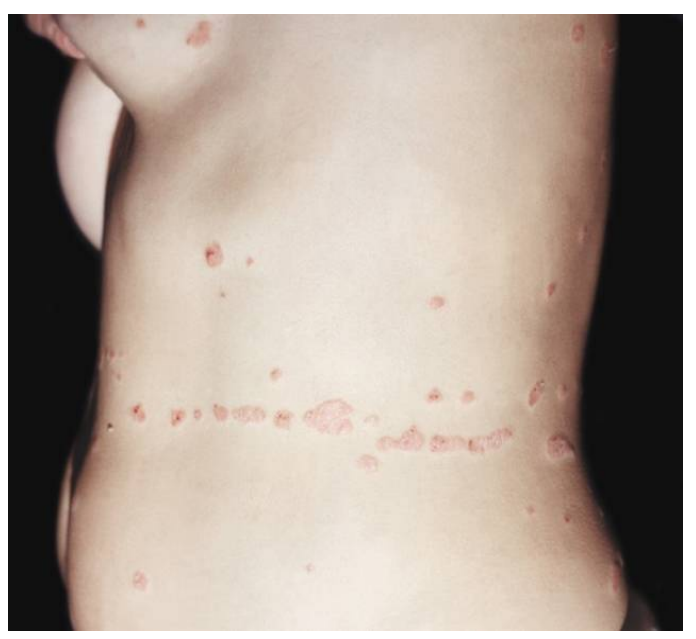

Фото 1

(http://www.nedug.ru/library/)

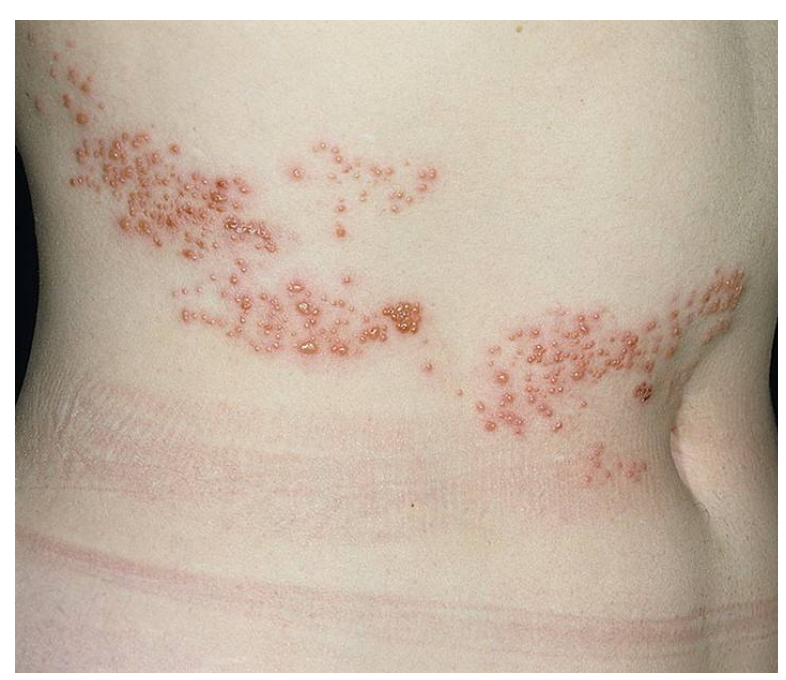

Фото 2

(http://dermline.ru/htm/92/92709.htm)

\section{«Биоэнергетические феномены» - ?}

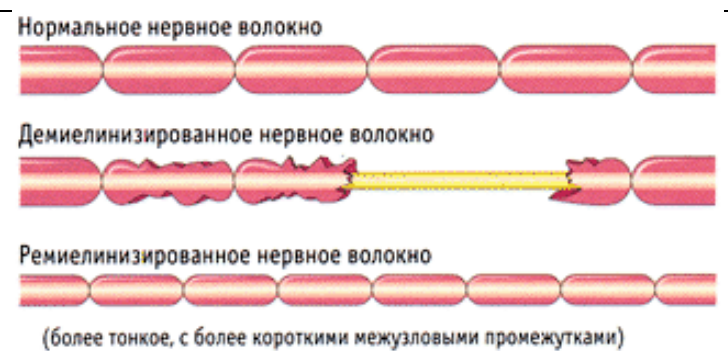

(http://uairs.org/more/)

Не исключено, что в таких демонстрационных проявлениях высыпаний на коже, которые изображены на фото-1 (псориаз - феномен Кебнера) и фото-2 (опоясывающий лишай высыпания «по ходу нерва») именно повреждение нервных волокон (демиелинизация) приводит к ухудшению передачи импульсов («биоэнергетический феномен») и потере некоторых фрункций, что и происходит во время возникновения/обострения заболевания.

После ремиелинизации передача импульсов восстанавливается, однако восстановление может быть неполным.

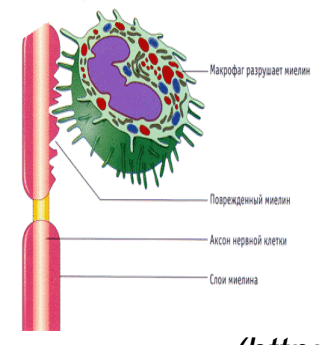

(http://uairs.org/more/)

Однако, к таким «биоэнергетическим феноменам» как нарушения проведения импульсов, аксотока в нервах и др., могут приводить и иммунные повреждения нервов: по неизвестной пока причине в некоторых случаях антигенпрезентирующие клетки (макрофраги) «ошибаются» и начинают атаковать клетки своего же организма или их фуннцию приобретают другие клетки (например, олигодендроцит); так возникают аутоиммунные повреждения; к наиболее известным и распространенным из них относятся - псориаз, ревматоидный артрит, рассеянный склероз и др.

Вышесказанное позволяет преположить, что «разгадка» данных френоменов может помочь «разгадать» причину и патогенез многих тяжелых заболеваний, лечение которых пока является малоэфффективным!!! 
Демонстрационные проявления высыпаний на коже

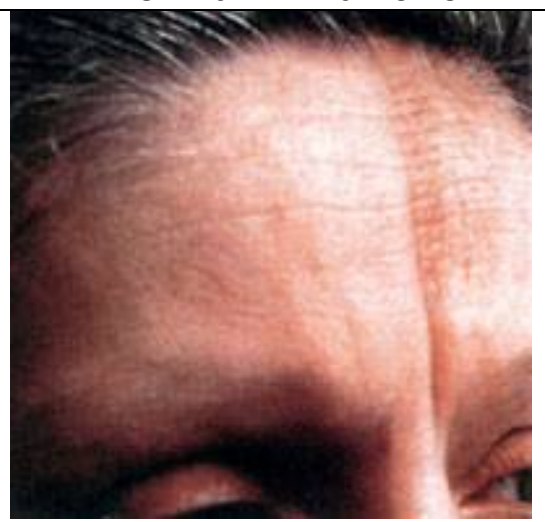

Фото 3

Склеродермия в виде т. н. «удара саблей»

С научной точки зрения акупунктурные меридианы не признаются, а рассматриваются как «меридианы» - в смысле удобной системы координат для поиска акупунктурных точек (согласно китайской натурфилософии). Однако, в некоторых случаях высыпания явно располагаются «не по ходу нервов» или каких-либо травм, а, действительно, напоминают расположение «по ходу акупунктурных меридианов». Этот вопрос дискутабельный и будет изучаться на страницах нашего журнала, тем более с «биоэнергетических точек зрения» (гипотезы последних лет о том, что это «пути миграции стволовых клеток» или «эмбриогенетические пути миграции», которые не проявляются гистологически, но могут быть регистрированы биоэнергетическими методами)
«Биоэнергетические феномены» - ?

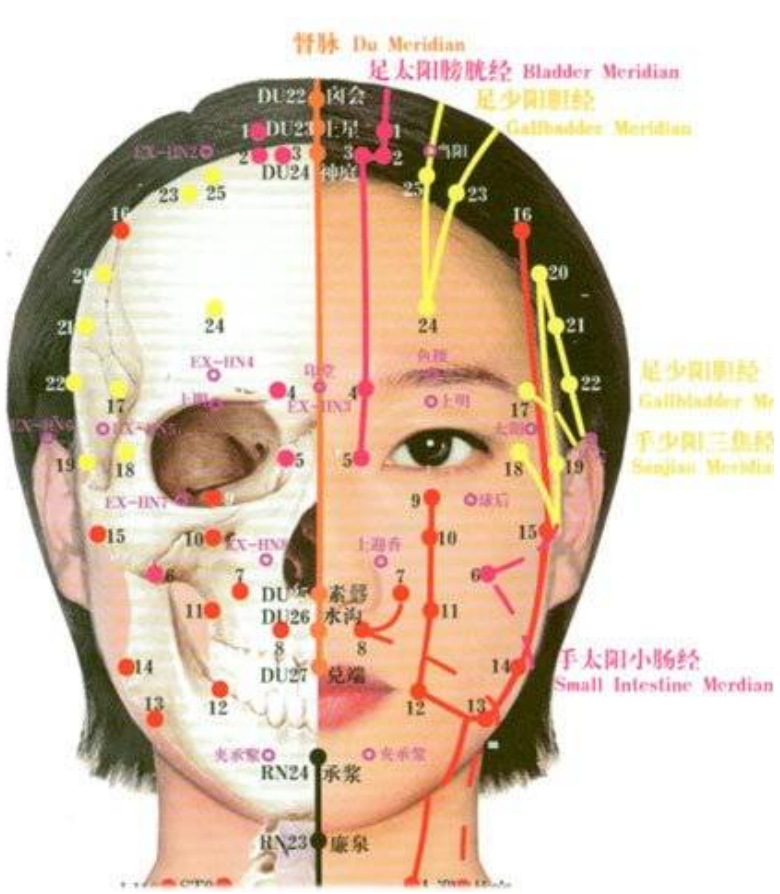

(http://ttonine.appspot.com/shemaakupunkturnyh-tochek-na-lice.html)

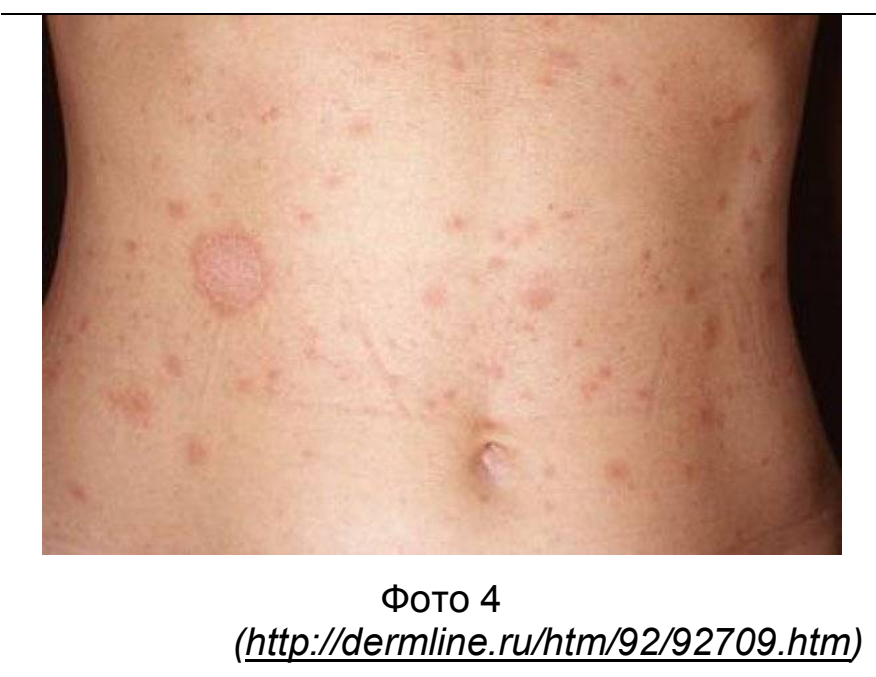

A

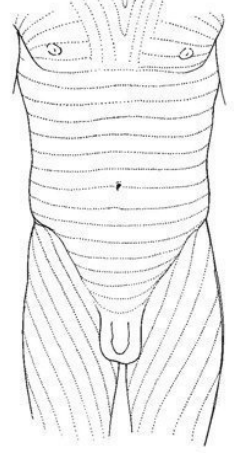

(http://medbe.ru/materials/)

(http://dermline.ru/htm/92/92709.htm)

Так называемое расположение высыпаний при розовом лишае Жибера по линиям Лангера 
Дальнейшие исследования в этом направлении могут позволить поновому рассматривать сущность многих кожных заболеваний и могут помочь в раскрытии механизмов развития ряда других заболеваний человека (нервной системы, иммунных и др.), в том числе - базируясь на «биоэнергетических» подходах к изучению данных проблем.

\section{תumepamypa:}

1.Атаман О. В. Венозна стінка: загальнотеоретичні й експериментальні аспекти / О. В. Атаман. - Суми: Видавництво СумДУ, Ангіо, 2001. - 248 с.

2. Атаман О. В. Патологічна фрізіологія в запитаннях і відповідях: навчальний посібник / О. В. Атаман - Видання 4-е, стереотипне. Вінниця: Нова Книеа, 2010. - 512 с.

3. Кубанова A. А. Иммуноморфология и морфогенез очагов пораженной кожи при псориазе / А. А. Кубанова, О. Р. Катунина // Вестник дерматологии и венерологии. - 2010. - № 1. - С. 70-79.

4. Патоморфрология болезней кожи: руководство для врачей / Г. М. Цветкова, В. В. Мордовцева, А. М. Вавилов, В. Н. Мордовцев // М.: Медицина, 2003. - 496 с.

5. Песляк М. Ю. Модель патогенеза псориаза. Часть 1. Системный псориатический процесс / М. Ю. Песляк. - М.: Эко-Трендз, 2010. - 72 c.

6. Судаков К. В. Нормальная физиология / К. В. Судаков. - М.: ООО «Медицинское информационное агентство», 2006. - 920 c.

Baker B. S. Recent Advances in PSORIASIS: The Role of Immune 7. System / B. S. Baker . - ICP Imperial College Press, 2000. - 180 p.

8. Chatterjee S. Role of 5'- and 3'-untranslated regions of mRNAs in human diseases / S. Chatterjee, J. K. Pal // Biology of the Cell. - 2009. - V. 101, N. 5. - P. 251-262. 


\section{References:}

1. Ataman O. V. Venozna stinka: zagal'noteoretychni j eksperymental'ni aspekty. Sumy: Vydavnyctvo SumDU, Angio, 2001, 248 p. [in Ukrainian].

2. Ataman O. V. Patologichna fiziologija $v$ zapytannjah $i$ vidpovidjah: navchal'nyj posibnyk (Vydannja 4-e, stereotypne). Vinnitsa: Nova Knyga, 2010, 512 p. [in Ukrainian].

3. Kubanova A. A., Katunina O. R. (2010). Immunomorfologiya i morfogenez ochagov porazhennoj kozhi pri psoriaze [Immunomorphology and morphogenesis of affected skin foci at psoriasis]. Vestnik Dermatologii $i$ Venerologii, 1, 70-79. [in Russian].

4. Cvetkova G. M., Mordovceva V. V., Vavilov A. M., Mordovcev V. N. Patomorfologiya boleznej kozhi: rukovodstvo dlya vrachej. Moscow: Medicina, 2003, 496 p. [in Russian].

5. Peclyak M. Yu. Model' patogeneza psoriaza. Chast' 1. Sistemnyj psoriaticheskij process. Moscow: Ehko-Trendz, 2010, 72 p. [in Russian].

6. Sudakov K. V. Normal naya fiziologiya [Normal Physiology]. Moscow: OOO Medicinskoe informacionnoe agentstvo, 2006, 920 p. [in Russian].

7. Baker B. S. Recent Advances in PSORIASIS: The Role of Immune System. ICP Imperial College Press, 2000, 180 p. [in English].

8. Chatterjee S., Pal J. K. (2009). Role of 5'- and 3'-untranslated regions of mRNAs in human diseases. Biology of the Cell, 101(5), 251-262. [in English]. 